\title{
Osler and the Way We Were Taught
}

\author{
Mary V. Seeman ${ }^{1} \cdot$ Robert E. Becker ${ }^{2}$
}

Published online: 30 May 2017

(C) International Association of Medical Science Educators 2017

The upcoming centennial of the death of Sir William Osler (1849-1919) makes this the perfect time to assess what remains of his teachings. Much has happened in medicine over these hundred years, and especially in the nearly 60 years since the two authors graduated together from McGill Medical School in 1960. Osler had studied and taught at McGill in the 1870s and early 1880s. Though our teachers never knew him, they were still guided, in the $1950 \mathrm{~s}$, by his approach to patient care, well-described in his 1892 textbook, The Principles and Practice of Medicine, and in over 1600 published articles, texts of speeches, and notes that his students took on bedside rounds.

Everyone agrees that Osler's greatest contribution to medicine was the recognition that physicians (whether students or old timers) learn more from their observations and conversations with patients than they do from books: "Medicine is learned by the bedside and not in the classroom" [1], and that is why our teachers, by their own example and by the critiques of our early interviews, taught us to ask open-ended questions and to listen attentively and respectfully while patients told their stories. This is akin to the modern naturalist's road to understanding behavior [2]. That same kind of listening, which has been called field observation, is no longer prevalent in medicine, probably because it takes time. It may also be that the spectacular advances in

Mary V. Seeman

mary.seeman@utoronto.ca

Robert E. Becker

Rebecker2008@comcast.net

1 Department of Psychiatry, University of Toronto, 260 Heath St. W, Toronto, ON M5P 3L6, Canada

27123 Pinebrook Road, Park City, UT 84098, USA molecular science made in the last 60 years, and the hitherto undreamt of technological breakthroughs, have made listening skills seem obsolete. The mistake is in thinking that technology or molecular dissection can capture the uniqueness of a person. Osler was a scientist who deeply appreciated the importance of seeing the whole, the unique person. Scientific evidence was essential but he always counseled medical students to "care more particularly for the individual patient than for the special features of the disease" [3].

Despite many attempts to include humanistic approaches in medical curricula, in today's medical interview rooms, it is not uncommon to hear patients grilled with a set of rapid-fire questions. Eye-to-eye contact is lost because the physician's eyes are glued to the computer screen, fingers busily entering data into electronic files. Building rapport with patients continues to be advocated in medical teaching via small group exercises and narrative medicine approaches, but the majority of students emerge from training having mastered only rote "empathic" expressions, "This must have been hard for you," repeated so glibly that they jar rather than comfort. This is neither empathic nor scientifically valid. Osler said: "The greatest enemy to the scientific practice of medicine is the practice of the routine" [4, p.359].

Osler belonged to the school of naturalist observation, much like his contemporary, Sir Charles Darwin. Before he was able to observe patients at the bedside, Osler had meticulously studied polyzoa in medical school [5]. He later reported on his work with Trichina spiralis: "My share was the detection of the 'worm' in its capsule; and I may justly ascribe it to the habit of looking-out, and observing, and wishing to find new things, which I had acquired in my previous studies of botany. All the men in the dissecting-rooms, teachers included, 'saw' the little specks in the muscles: but I believe that I alone 'looked-at' them and observed them: no one trained in natural history could have failed to do so" [4, p.59]. 
This is a good example of Osler, the naturalist, observing worms. He approached human beings in much the same way, through painstaking observation of his patients, and active listening (which he could not do with worms).

Osler was first and foremost a scientist. He never accepted his clinical diagnoses as final without confirming them through biopsies or autopsies. He famously said, "The practice of medicine is an art based on science" [6], meaning that, although understanding physiological processes is fundamental to medicine, paying attention to a person's hopes and dreams is the more difficult skill to acquire. Following Osler, we were taught to listen not only for a description of symptoms but also for ruptures in the autobiography [7] that represented a person's goals and ambitions interrupted by illness. This approach is captured in Osler's precept: "learning at the patient's bedside, observation, cautious induction, confirmation of impressions from patients, library, and laboratory, expansion of knowledge by correlation of autopsy findings with clinical observations, and working with a love of every person equally without regard to rank" [8].

Patients, as a rule, want to understand the meanings behind their illnesses "Why me?", "Why now?", "What lesson is this meant to teach me?", "What did I do to deserve this?". They hope to engage their physicians in the quest for answers, but physicians today are more interested in questions they can more easily answer: "What genes?", "What proteins?", and "What nerve pathways?" Existential queries are dismissed as humanistic marginalia, no longer central, as they once were, to medical practice. Psychotherapy, the art of assisting patients in finding meaning and self-understanding, once a core skill in psychiatry, and the treatment most valued by patients [9], is no longer a required component of psychiatric training in the USA [10]. And psychiatry is the specialty that once rightly prided itself as emblematic of humanistic practice.

In the tradition of Osler, we learned in medical school to search in patient stories for the significant life details that trigger illness and disability. We learned to be sensitive to the far-reaching effects of loss and mourning. Today, medical students are still taught to question their patients about life events, but only whether or not they have occurred, not about their significance. Modern animal behaviorists and primatologists since Konrad Lorenz have become more sensitive to the critical roles played by emotion and social connectedness [11] than today's physicians, who tend to relegate such forces to the realm of magic. Emotions and relationships are considered not sufficiently evidence-based for today's generation of young clinical scientists because they cannot easily be imaged, quantified, replicated, averaged, and graphed. It is the primatologists today, rather than the physicians, who focus on the colorful variation within species and the uniqueness of the individual.

Variation was a cornerstone of medical science for Osler, just as it was for his contemporary, Darwin, in his search for the origins of Homo sapiens. Osler wrote: "Variability is the law of life, and as no two faces are the same, so no two bodies are alike, and no two individuals react alike and behave alike under the abnormal conditions which we know as disease" [12]. It is for this reason that he studied patients in depth and did not consider them merely as "cases," or representatives of a disease category. We never heard patients referred to as "cases" until after our graduation from medical school, until after we settled in corners of our two countries where the teachings of William Osler seemed to have been forgotten [13].

In our student days, we were made to understand that the doctor-patient relationship was critical, that the power of that relationship could buffer stress and reduce the ill effects of disease. We learned that interactions with physicians could exert a profound influence on human health and wellbeing. As an example, Golden [14] tells a very revealing story about Osler and a child patient. The child was at death's door from diphtheria and had stopped eating; Osler was called in as a consultant. Because of his busy schedule (he had been on his way to a university function), he stopped to see the child dressed in his academic gowns. The child was awed by the attire and, in this transfixed state, automatically swallowed the spoonfuls of food that Osler offered. Osler dressed in his gown every day to visit the boy and to feed him, and continued to do so until the boy was out of harm's way.

We learned at McGill to let our feelings show, to not be embarrassed when brought to tears by our patients' losses, to be proud of our patients' shows of strength, to be happy when the news was good and supportive when it was difficult to bear, to instill much-needed hope when the future looked dim. We learned to be empathic listeners making use of our personal emotions, tempered with Oslerian equanimity, as a tool to understand our patients and their situation. The expectations the public has of physicians, Osler wrote, are "self-sacrifice, devotion, love and tenderness to your fellow-men" [6].

We were taught to treat all patients with respect, to value their dignity at all times, to recognize their diversity, and their intrinsic personal worth no matter the symptoms or life styles. We were students at a time when medicine's traditions framed our roles as new doctors who would always remain students of medicine, continuously re-educated by learning from the patients we saw. "It goes without saying that no man can teach successfully who is not at the same time a student" [15]. We were students at a time when the World Health Organization recognized health as a primary aim of medical care, and we were taught that our aim was not only accurate diagnosis and effective treatment, but, before all else, our patients' wellbeing.

Matters today seem so different. As Osler said, "The philosophies of one age have become the absurdities of the next, and the foolishness of yesterday has become the wisdom of tomorrow" [3, pp. 277-306]. Over recent years, interest in the lost practices that marked us and defined us comes mainly from the fast diminishing ranks of the humanities; it is so rarely these days expressed within the medical sciences. For us, humanism 
was not a frivolous side issue but the very foundation on which medicine was built and from which it evolved. History taking and careful observation (not laboratory results) were the authority upon which differential diagnoses and initial treatment plans were built. Laboratory tests confirmed (or not) our hypotheses, not the other way around.

It is perhaps in the domain of chronic illness that Osler's teachings are most apropos today. By the time we entered medical school, acute illnesses such as the pneumonia that precipitated Osler's own death had become fully treatable with drugs not available in the days of Osler. Nowadays, medicine is largely engaged in the application of modern resources to manage chronic illness. But successful management of chronicity depends less on modern resources than it does on the patient's engagement in his or her own care. This is where Osler's lessons become critical - listen to the patient, make an effort to understand the uniqueness of the patient, spend time with the patient, share knowledge with the patient, laugh and cry with the patient, and use the leverage of the clinician-patient relationship to motivate the patient. Only then will the patient take the necessary steps to further his or her own health and wellbeing. Animal biologists have known for a long time that studying their subjects when they are in captivity does not yield results applicable to animals in the wild [2]. Osler recognized that this held for human beings. In order to gain their cooperation, patients need to be approached "in the wild," (wo)man to (wo)man, away from the constraints of laboratory tests, medical jargon, technology, and statistics. Framing health in terms of personal goals, family ties, and cultural traditions will engage patients in the prevention and management of chronic illness in a way that actuarial figures and molecular pathways cannot.

It has been our experience in the years of practice, teaching, and research since graduation that patient care has suffered since physicians lost contact with their Oslerian roots. Many medical schools continue to emphasize empathy for patients' personal, economic, social, cultural, and community circumstances. From these emphases, students learn the social as well as the molecular mechanisms of diseases. They learn not only from lectures and texts and videos but also from welltrained simulated patients. These and other tools for mastering human diseases - self-directed small group learning, stints in the laboratory, community health projects, patient advocacy experiences - all constitute rich learning experiences. They complement but cannot replace one-to-one patient care, where the focus is on each person's uniqueness. Osler taught us to bring modern science into each individualized encounter with a patient. Our science is far broader in scope than his, but we have lost Osler's naturalistic context. His example has faded and died away.

Osler's actual death is a telling example of how medicine has changed since his time. He died from pneumonia while stricken with grief at the loss of his son, Revere, who was killed at the front in World War I [16]. His grief was compassionately attended to, but his life could not be saved because there were no antibiotics. Nowadays, pneumonia rarely kills, but family problems, emotional losses, spirituals queststhese are now largely ignored by physicians. This is not the way we were taught. Scientific discoveries need to enhance, not replace, the art of medicine.

\section{References}

1. Thayer WS. Osler the teacher. In: Thayer WS, editor. Osler and other papers. Baltimore: Johns Hopkins Press; 1931. p. 1-15.

2. De Waal FB. How animals do business. Sci Am. 2005;292:72-7.

3. Osler W. Aequanimitas with other addresses to medical students, nurses and practitioners of medicine. Blakiston, Philadelphia. 1904.

4. Cushing H. The life of Sir William Osler, vol. 1. Severis, Germany. 2010. (originally published 1940).

5. Osler W. On Canadian fresh-water polyzoa. Read before the natural history Society of Montreal. 1877. Pub Canadian Nat. 1883, 399406.

6. Silverman M, Murray TJ, Bryan C. The quotable Osler. Philadelphia: American college of physicians; 2003.

7. Eneman M, Vanhee L, Liessens D, Luyten P, Sabbe B, Corveleyn J. Humanistic psychiatry and psychotherapy: listening to patients as persons in search of meaning. The case of schizophrenia. J Humanist Psychol. 2016; doi:10.1177/0022167816637291.

8. Becker RE. Remembering sir William Osler 100 years after his death: what can we learn from his legacy? Lancet. 2014;384: 2260-3.

9. Lauber C, Nordt C, Falcato L, Rössler W. Lay recommendations on how to treat mental disorders. Soc Psychiatry Psychiatr Epidem. 2001;36:553-6.

10. Binder R. Should psychotherapy remain part of psychiatry? Psychiatric News http://psychnews.psychiatryonline.org/doi/full/ 10.1176/appi.pn.2016.2a11. Accessed 17 Feb 2017.

11. Evans RI, Lorenz K. Konrad Lorenz: The man and his ideas. Harcourt. San Diego; 1975.

12. Osler $\mathrm{W}$. On the educational value of the medical society. In: Aequanimitas with Other Addresses to Medical Students, Nurses and Practitioners of Medicine, Blakiston, Philadelphia. 1904. P. 343-62.

13. Becker RE. PTSD: a disorder and a reaction. Am J Psychiatry. 2005;162:2215-9.

14. Golden RL. William Osler at 150: an overview of a life. JAMA. 1999;282:2252-8.

15. Osler W. A Way of Life. Constable \& Co. Ltd. 1913. p. 326.

16. Starling PH. The case of Edward revere Osler. J R Army Med Corps. 2003;149:27-9. 